\title{
Does COVID-19 really make people risk aversion in investment decision-making?
}

\author{
Muhammad Shadab Iqbal ${ }^{1}$, and $\operatorname{Lin} \mathrm{Li}^{2, *}$ \\ ${ }^{1}$ Graduate School of Venture, Hoseo University, Seoul, Korea \\ ${ }^{2}$ College of Business Administration, Kookmin University, Seoul, Korea
}

\begin{abstract}
The economic fallout from COVID-19 pandemic changes individuals' investment perceptions and behaviors in a tremendous way. Consequently, investment decision-making has been affected as people have to adjust to the new environment. This study aims to study whether COVID19 really make people risk aversion due to the economic slowdown. Our empirical results are analyzed from household finance data in U.S in July 2021. It is found that COVID-19 proximity, income, and occupation are positively associate with risking taking in investment decision-making, while age and family size are not. This study contributes to the newly emerged body of knowledge on post pandemic investment decision-making and risk behavior analysis and provide implications for financial investment institutions.
\end{abstract}

Keywords: Risk aversion, Risk taking, Investment decision-making, COVID-19 pandemic

\section{Introduction}

Coronavirus (COVID-19) pandemic has swept the globe and affected nearly all aspects of life, from economic to politics, from workplace to everyday activities. For example, the unemployment rates are on the rise in many counties and most of countries are in recession. The International Monetary Fund (IMF) estimated that the world economy declined by $4.4 \%$ in 2020, which is the worst since the Great Depression in the 1930s [1].

The economic fallout from COVID-19 changes individuals' investment perceptions and behaviors in a tremendous way. Consequently, investment decision-making has been affected as people have to adjust to the new environment. Risk perception shows how risks are interpreted from different thoughts and reality [2]. Risk perception plays a vital role in influencing household behavior, especially in investment decision making among uncertain environment [3]. It is important to study the influence of a negative shock (COVID-19 in this case) on households, which are essential to the economic system in the micro level. Individuals in households' response to the pandemic both in perceptions and behaviors, which demand more research to obtain a better understanding of the household financial investment decision-making response to the negative shock.

\footnotetext{
* Corresponding author: $\underline{\text { ilin } @, k o o k m i n . a c . k r}$
} 
The research gap is that limited number of related studies have mixed results on risk aversion or risk taking during COVID-19 pandemic. For example, it is found that households tend to become risk aversion amidst the COVID-19 [4]. However, it is discovered that individuals' risk tolerance increase for the early stages of COVID-19 by using an incentivized experiment [5], and one study found that there is no change in risk aversion or risk taking in a risk elicitation task during COVID-19 [6].

The mixed results intrigue this study to study whether COVID-19 really make people risk aversion in the investment decision-making due to the economic slowdown. This study contributes to the newly emerged body of knowledge on post pandemic investment decisionmaking and risk behavior analysis and provide implications for financial investment institutions.

\section{Methodology}

\subsection{Data collection}

The data is collected from 200 household finance data across the U.S. through Amazon Mechanical Turk (MTurk) service in July 2021. MTurk is a gig economy platform and serves as a crowdsource website and a digital labor platform [7]. Survey data from MTurk is found to have no significant difference in terms of reliability when compared to other survey methods [8].

The potential problem of using MTurk is that participants receive payments may influence the objectivity of the data. However, it is argued that respondent's extrinsic motivation with the payment is not a major concern if a reasonable payment is given for the time spending on answering the questions [9]. In this study, USD 50 cents were paid to the participants for using 4 to 5 minutes of their time, which indicate that the representativeness of the data sample is not a major concern.

\subsection{Empirical model}

This study follows the extant study [4] and uses logistic regression analysis model for analysis. The model for the empirical analysis is shown as below:

$$
\mathrm{Y}_{\mathrm{i}}=\alpha+\text { income }_{\mathrm{i}}+\text { family size }_{\mathrm{i}}+\text { age }_{\mathrm{i}}+\text { occupation }_{\mathrm{i}}+\text { covid proximity }_{\mathrm{i}}+\mathrm{z}_{\mathrm{i}}+\varepsilon_{i}
$$

Where $Y_{i}$ is the dependent variable (i.e., risk aversion as 0 and risk taking as 1 ), $Z i$ is a set of control variables, and $\varepsilon_{i}$ is an idiosyncratic random error for a household $i$.

\subsection{Measurement of variables}

For independent variables, income is measured by 9 groups, family size is measured by how many members are in a household, and age is measured by 7 age groups. Occupation is measured by 7 groups, the bigger the number is, the closer the job is related to white-collar, service, and financial related jobs. The COVID proximity is measured by the number of COVID-19 cases per 100,000 people in the neighbourhood based on home postal code in the U.S., where 1 indicates low proximity and 7 indicates high proximity.

For the control variables, education is measured in 7 groups, and gender is measured by 2 groups, 1 indicates females and 2 indicates males.

As to the dependent variable, investing in safe-haven and traditional assets (such as gold) for more than $50 \%$ in the household investment portfolio is considered as risk aversion and 
it is measured as 0 . On the other hand, investing more than $50 \%$ in emerging and risker assets (such as cryptocurrency) is regarded as risk taking in the household investment decisionmaking and it is measured as 1 .

\section{Results and Discussion}

\subsection{Logistic regression analysis}

Logistic regression analysis model is used in this study. Since the dependent variable was coded as 0 (risk aversion) or 1 (risk taking), logistic regression analysis was chosen because the outcome variable is based on logit equivalent [10]. In addition, the maximum likelihood estimation (MLE) was used to estimate the path coefficients. The model is shown as below:

$$
\operatorname{In}\left[\frac{\mathrm{P}\left(y_{i}=1\right)}{\mathrm{P}\left(y_{i}=0\right)}\right]=b_{0}+b_{1} x_{1}+b_{2} x_{2}+\cdots+b_{n} x_{n}
$$

Where $x_{l}$ to $x_{n}$ are the $n$ predictors, $y_{i}$ is the outcome.

\subsection{Data analysis results}

Summary statistics are shown in Table 1 as below. Number of objects, mean value, standard deviation, maximum value, and minimum value are included in the summary statistics.

Table 1. Summary statistics

\begin{tabular}{|c|c|c|c|c|c|}
\hline Variables & Obs & Means & Std. & Min. & Max. \\
\hline Income & 200 & 3.74 & 0.132 & 1 & 9 \\
\hline Family Size & 200 & 4.98 & 0.112 & 1 & 7 \\
\hline Age & 200 & 5.54 & 0.080 & 1 & 7 \\
\hline Occupation & 200 & 2.50 & 0.102 & 1 & 7 \\
\hline COVID & 200 & 4.91 & 0.115 & 1 & 7 \\
\hline Education & 200 & 3.36 & 0.106 & 1 & 7 \\
\hline Gender & 200 & 1.50 & 0.035 & 1 & 2 \\
\hline
\end{tabular}

Source: Own processing.

Before testing the hypotheses, correlation analysis and a multicollinearity test were conducted, and the results are shown in Table 2. If the correlation between two variables is above 0.80 , it is problematic [11]. The correlation matrix indicates that the highest value of the correlation coefficient was 0.359 , showing acceptable correlations among variables. In addition, the variance inflation factor (VIF) values were checked for multicollinearity. The VIF values of this study varied from 1.047 to 1.241 , which is less than the threshold value of 5.0 [12], meaning no multicollinearity issue.

Table 2. Correlations and results of multicollinearity analysis

\begin{tabular}{|c|c|c|c|c|c|c|c|c|}
\hline & $\mathbf{( 1 )}$ & $\mathbf{( 2 )}$ & $\mathbf{( 3 )}$ & $\mathbf{( 4 )}$ & $\mathbf{( 5 )}$ & $\mathbf{( 6 )}$ & (7) & VIF \\
\hline $\begin{array}{c}\text { Income } \\
\text { (1) }\end{array}$ & 1 & & & & & & & 1.241 \\
\hline $\begin{array}{c}\text { Family } \\
\text { Size (2) }\end{array}$ & $0.142^{*}$ & 1 & & & & & & 1.092 \\
\hline $\begin{array}{c}\text { Age } \\
\text { (3) }\end{array}$ & $0.171^{*}$ & $0.187^{* *}$ & 1 & & & & & 1.088 \\
\hline
\end{tabular}




\begin{tabular}{|c|c|c|c|c|c|c|c|c|}
\hline $\begin{array}{c}\text { Occupa } \\
\text { tion (4) }\end{array}$ & $0.225^{* *}$ & -0.041 & 0.136 & 1 & & & & 1.081 \\
\hline $\begin{array}{c}\text { COVID } \\
\text { (5) }\end{array}$ & $0.359^{* *}$ & $0.214^{* *}$ & 0.145 & $0.144^{* *}$ & 1 & & & 1.221 \\
\hline $\begin{array}{c}\text { Educati } \\
\text { on (6) }\end{array}$ & $0.180^{*}$ & 0.046 & -0.052 & 0.055 & 0.113 & 1 & & 1.047 \\
\hline $\begin{array}{c}\text { Gender } \\
\text { (7) }\end{array}$ & 0.079 & 0.029 & -0.005 & 0.017 & $0.149^{*}$ & 0.001 & 1 & 1.025 \\
\hline
\end{tabular}

${ }^{*} p<0.05 ; * * p<0.01$

Source: Own processing.

The logistic analysis results are shown in Table 3. Model 1 has only the control variables, and both control variables were significantly related to risk taking: education $(\beta=0.234$, $p<0.005)$, gender $(\beta=0.705, p<0.005)$. The results mean that the higher the education level is, the higher chance that risk will be taken in the investment decision-making. Moreover, males are more likely to take risk than females in the investment decision-making.

Model 2 includes the independent variables, and the Cox \& Snell $R^{2}$ was increased from 0.056 to 0.629 , and Nagelkerke $R^{2}$ was increased from 0.075 to 0.849 , indicating the strength of connections between the independent variables and the dependent variables increase significantly. Income $(\beta=2.219, p<0.001)$, occupation $(\beta=0.770, p<0.001)$, and COVID proximity $(\beta=1.025, p<0.01)$ were significantly related to risk taking. While family size $(\beta=0.049, p>0.05)$ and age $(\beta=-0.549, p>0.05)$ were not significantly related to risk taking.

Table 3. Results of logistic regression analysis

\begin{tabular}{|c|c|c|c|c|c|c|}
\hline \multirow{2}{*}{$\begin{array}{c}\text { Dependent } \\
\text { variable: Risk } \\
\text { Aversion (0) or } \\
\text { Risk Taking (1) }\end{array}$} & \multicolumn{3}{|c|}{$\begin{array}{c}\text { Model 1 } \\
\text { (Control variables) }\end{array}$} & \multicolumn{3}{|c|}{$\begin{array}{c}\text { Model 2 } \\
\text { (Model 1 + Independent } \\
\text { variables) }\end{array}$} \\
\hline & $\mathrm{B}$ & $\begin{array}{c}\text { Standard } \\
\text { Error (SE) }\end{array}$ & $p$-value & B & SE & $p$-value \\
\hline \multicolumn{7}{|c|}{ Control variables } \\
\hline Education & 0.234 & 0.099 & $0.018^{*}$ & 0.353 & 0.221 & 0.110 \\
\hline Gender & 0.705 & 0.292 & $0.016^{*}$ & 1.815 & 0.682 & 0.008 \\
\hline \multicolumn{7}{|c|}{ Independent variables } \\
\hline Income & & & & 2.219 & 0.366 & $0.000^{* * *}$ \\
\hline Family Size & & & & 0.049 & 0.224 & 0.827 \\
\hline Age & & & & -0.549 & 0.296 & 0.063 \\
\hline Occupation & & & & 0.770 & 0.240 & $0.001^{* * *}$ \\
\hline COVID Proximity & & & & 1.025 & 0.253 & $0.000^{* * *}$ \\
\hline Constant & 1.805 & 0.582 & 0.002 & 15.935 & 3.192 & $0.000^{* * *}$ \\
\hline$R^{2}$ (Nagelkerke) & \multicolumn{3}{|c|}{0.075} & \multicolumn{3}{|c|}{0.849} \\
\hline$R^{2}($ Cos \& Snell $)$ & \multicolumn{3}{|c|}{0.056} & \multicolumn{3}{|c|}{0.629} \\
\hline d.f. & \multicolumn{3}{|c|}{2} & \multicolumn{3}{|c|}{2} \\
\hline$P$ & \multicolumn{3}{|c|}{0.003} & \multicolumn{3}{|c|}{0.003} \\
\hline $\begin{array}{c}-2 \text { Log Likelihood } \\
\text { Ratio }\end{array}$ & \multicolumn{3}{|c|}{265.650} & \multicolumn{3}{|c|}{78.797} \\
\hline
\end{tabular}

Notes: ${ }^{*} p<0.05 ; * * p<0.01 ; * * * p<0.001$

Source: Own processing. 


\subsection{Discussion of results}

The interpretations of our findings are described as below. First, it is interesting to find out that the higher proximity of COVID-19 is in terms of COVID-19 cases in the neighbourhood per 100,000 people, the higher chances are that people are more risk taking in their investment decision-making. The possible explanation is that households may become risk aversion amidst the COVID-19 [4], or no change in risk aversion or risk taking during COVID-19 [6] in general as extant studies found out. But we believe that when there are actually more COVID-19 cases in the neighborhood, people might consider the COVID-19 pandemic as a more concrete event due to a short spatial distance [13], thus process and analyze the investment plans more carefully, resulting in associating risks as low-level means [13], which indicates increasing the risk tolerance [5] and taking more risks in their financial decisionmaking. On the contrary, if there are less cases in the neighborhood, the COVID-19 pandemic could be processed as a dreadful event that happens far away, which results in associating risks as high-level means [13], indicating less mental process is used in the financial decisionmaking process and resulting in less changes in the risk tolerance.

Second, income and occupation are found to be positively associated with risk taking in the investment decision-making during the COVID-19 pandemic. The higher the income is, the higher chance individuals take more risks in investment decision-making, the possible explanation is that individuals with more disposable income could afford to take bigger risks with their investments. As to the occupation, we found that when the jobs are more whitecollar, service, and financial related, more risks could be accepted in the investment decisionmaking, the reason could be that more financial knowledge makes it comfortable to accept volatility in their investment portfolios and make risker decisions in their investments.

Third, family size and age are found to be not significantly associated with risk taking in the investment decision-making during the COVID-19 pandemic. The findings are consistent with [14] that the number of children nor the number of dependents influence the level of risk tolerance. As to the age, there is a tendency that the older the individuals are, the less likely they would like to take risks in their investment decision-making, yet the associate is not significant.

\section{Conclusion}

In conclusion, this study found that COVID-19 proximity, income, and occupation are positively associate with risking taking in investment decision-making, while age and family size are not. COVID-19 pandemic may be considered as a concrete event and raise risk tolerance if there are more cases in the neighborhood despite the economy uncertainty that has caused by the pandemic in general. Therefore, COVID-19 pandemic does not necessarily make people more risk aversion as expected. In addition, whether households take more risk in their investment decision also related positively with income and occupation, but not with age and family size.

This study contributes to the newly emerged body of knowledge on post pandemic investment decision-making and risk behavior analysis and provide implications for financial investment institutions. Even though it is important to invest in safe-haven assets through various times and situations, it cannot be assumed that households naturally become risk aversion due to the COVID-19 pandemic. Therefore, financial investment institutions should not only focus on finding safe-haven assets, but also finding emerging assets that could benefit the returns of individuals in a timely manner. 


\section{References}

1. L. Jones, D. Palumbo, D. Brown, Coronavirus: How the pandemic has changed the world economy [online], Available at: https://www.bbc.com/news/business-51706225 (2021)

2. A. Nadya Septi Nur, L. Lutfi, The influence of risk perception, risk tolerance, overconfidence, and loss aversion towards investment decision making. Journal of Economics, Business, \& Accountancy Ventura, 21(3), 401-413 (2019)

3. D. Forlani, J. W. Mullins, Perceived risks and choices in entrepreneurs' new venture decisions. Journal of business Venturing, 15, 305-322 (2000)

4. P. Yue, A. Gizem Korkmaz, H. Zhou, Household financial decision making amidst the COVID-19 pandemic. Emerging Markets Finance and Trade, 56(10), 2363-2377 (2020)

5. J. Shachat, M. J. Walker, L. Wei, The impact of the Covid-19 pandemic on economic behaviours and preferences: Experimental evidence from Wuhan. ESI Working Paper, 20(33) (2020)

6. M. Angrisani, M. Cipriani, A. Guarino, R. Kendall, J. Ortiz de Zarate, Risk preferences at the time of COVID-19: an experiment with professional traders and students. FRB of New York Staff Report, 927 (2020)

7. T. M. Daly, R. Nataraajan, Swapping bricks for clicks: Crowdsourcing longitudinal data on Amazon Turk. Journal of Business Research, 68(12), 2603-2609 (2015)

8. M. Buhrmester, T. Kwang, S. D. Gosling, Amazon's Mechanical Turk: A new source of inexpensive, yet high-quality data? Perspectives on Psychological Science, 6(1), 3-5 (2016)

9. P. B. Lowry, J. D’Arcy, B. Hammer, G. D. Moody, "Cargo Cult" science in traditional organization and information systems survey research: A case for using nontraditional methods of data collection, including Mechanical Turk and online panels. The Journal of Strategic Information Systems, 25(3), 232-240 (2016)

10. S. Banerjee, A. Y. Chua, A theoretical framework to identify authentic online reviews. Online Information Review, 38(5), 634-649 (2014)

11. M. Licht, Multiple regression and correlation.In L.G. Grimm \& P.R. Yarnold (Eds.), Reading and understanding multivariate statistics, Washington, DC, American Psychological Association, 19-64 (1995)

12. M. A. Schroeder, J. Lander, S. Levine-Silverman, Diagnosing and dealing with multicollinearity. Western Journal of Nursing Research, 12(2), 75-187 (1990)

13. Y. Trope, N. Liberman, Construal-level theory of psychological distance. Psychological Review, 117(2), 440-450 (2010)

14. T. A. Hallahan, R. W. Faff, M. D. McKenzie, An empirical investigation of personal financial risk tolerance. Financial Services Review-greenwich, 13(1), 57-78 (2004) 